\title{
Nandrolone decanoate relieves joint pain in hypogonadal men: a novel prospective pilot study and review of the literature
}

\author{
Alexander J. Tatem ${ }^{1}$, Levi C. Holland ${ }^{2}$, Jason Kovac ${ }^{1}$, Jonathan A. Beilan ${ }^{3}$, Larry I. Lipshultz ${ }^{4}$ \\ ${ }^{1}$ Men's Health Center, Urology of Indiana, Greenwood, IN, USA; ${ }^{2}$ McGovern Medical School, University of Texas Health Science Center, Houston, \\ TX, USA; ${ }^{3}$ Advanced Urology Institute, Clearwater, FL, USA; ${ }^{4}$ Scott Department of Urology, Baylor College of Medicine, Houston, TX, USA \\ Contributions: ((I) Conception and design: All authors; (II) Administrative support: All authors; (III) Provision of study materials or patients: AJ Tatem, \\ JA Beilan, LI Lipshultz; (IV) Collection and assembly of data: All authors; (V) Data analysis and interpretation: All authors; (VI) Manuscript writing: \\ All authors; (VII) Final approval of manuscript: All authors. \\ Correspondence to: Alexander J. Tatem, MD. Men's Health Center, Urology of Indiana, 679 East County Line Road, Greenwood, IN 46143, USA. \\ Email: atatem@urologyin.com.
}

\begin{abstract}
Testosterone is an archetypal androgenic-anabolic steroid (AAS), while its exogenous administration is considered to be the gold standard for the treatment of male hypogonadism. The benefits are not due to its intrinsic nature alone but are due to the result of its interactions with the androgen receptor (AR). As the management of hypogonadism continues to advance into the modern era, it would be preferable for modern andrologists to have multiple tools at their disposal to influence AR activity. Nandrolone, or 19-nortestosterone, is one such compound. In the following review of the literature, we examine the history, pharmacology, and clinical applications of this medication. We also present the results of our novel pilot study examining the favorable effects of nandrolone on joint pain for hypogonadal men.
\end{abstract}

Keywords: Nandrolone; testosterone; andrology; hypogonadism; joint pain; arthritis; testosterone deficiency

Submitted Oct 11, 2019. Accepted for publication Oct 31, 2019.

doi: $10.21037 /$ tau.2019.11.03

View this article at: http://dx.doi.org/10.21037/tau.2019.11.03

\section{Introduction}

Testosterone is an essential component for male development and well-being and is the prototypical androgenic-anabolic steroid (AAS). As a result of the intricate interplay of the hypothalamic-pituitary-gonadal (HPG) axis, testosterone is primarily produced by the testicles and exerts both local and systemic effects (1). Its deficiency, also known as hypogonadism, has been linked to multiple pathologies including low libido, erectile dysfunction (ED), fatigue, and irritability $(1,2)$. Hypogonadism has also been linked to significant metabolic derangements with hypogonadal men displaying decreased lean body mass, reduced strength, and elevated fat mass compared to their eugonadal counterparts (3-5). This increased fat mass then creates a 'vicious cycle' whereby increased aromatase activity from adipocytes leads to a hyperestrogen state that further suppresses the HPG axis and normal endogenous testosterone production. This phenomenon can often propel hypogonadal men towards metabolic syndrome and may explain why hypogonadism has recently been shown to be an independent risk factor for cardiovascular disease (CVD) (6-8). Fortunately, restoration of eugonadal testosterone levels via testosterone therapy (TTh) can improve insulin resistance and hemoglobin A1c $(9,10)$.

The revelation regarding testosterone's beneficial properties has spawned the field of modern andrology. However, it is important to note that the observed benefits seen with testosterone do not manifest in isolation but rather are the result of its interaction with the male androgen receptor (AR). Ideally, modern andrologists should be able to expand their armamentarium with other AAS that exert differential effects on the AR. Although several other AAS have been synthesized over the years, their varying effects, physiologic benefits, and risk 


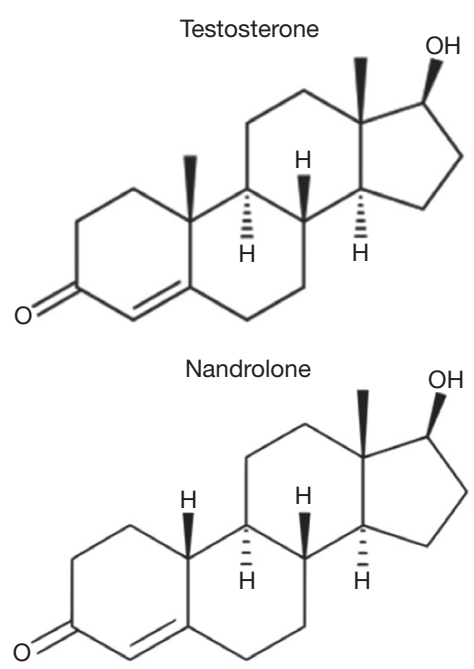

Figure 1 Comparative organic structure of testosterone and nandrolone (13).

profiles have been poorly characterized (11); one of these compounds is 19 -nortestosterone, which is also known as nandrolone. In the following review and novel pilot study, we examined the available literature regarding nandrolone's use in men and investigated novel indications and benefit from its use in the treatment of hypogonadal men.

\section{Background}

Nandrolone was first synthesized and described by Birch in 1950 (12). It is identical in structure to testosterone except for one minor but crucial difference, the lack of one methyl group at carbon C-19 (Figure 1). The androgenic and myogenic activity of testosterone and other AAS such as nandrolone was the subject of much investigation during the 1950s-1960s. Shortly after nandrolone's synthesis was first described, Eisenberg and Gordan developed a method of indexing and characterizing the relative myotrophicandrogenic (MA) activities of various exogenous AAS. By comparing the differential weights of the levator ani musculature and seminal vesicles of rats treated with AAS to controls, they were able to establish a MA index for each compound they examined (14). Testosterone, being the original AAS, was assigned a MA index of 1 , meaning that it was perceived to exert equal androgenic and myogenic effects $(11,15)$. By comparison, nandrolone was found to possess a MA index of roughly 11 and as such, was observed to be exponentially more anabolic than testosterone itself $(15,16)$. This significant increase in myogenic activity has been theorized to be related to its metabolism by $5 \alpha$-reductase in androgenic tissues $(11,13) .5 \alpha$-reductase is highly expressed in the prostate, hair follicles, and other androgenic tissues but negligibly expressed in skeletal muscle (11). While testosterone's $5 \alpha$-metabolite, dihydrotestosterone (DHT), has a very high affinity for the AR, nandrolone's $5 \alpha$-metabolite, $5 \alpha$-dihydro-19-nortestosterone, has a significantly lower affinity, even lower than nandrolone itself (17). Thus, the conversion of nandrolone to its $5 \alpha$-metabolite results in a characteristically different AR activation in androgenic tissues when it was compared to testosterone and DHT with specifically preserved AR activation in skeletal muscle. This discrepancy in AR activity amongst varying tissues serves as the basis behind nandrolone's potential modern clinical applications.

\section{Historical clinical applications}

Nandrolone was initially FDA approved in 1962 for the treatment of anemia resulting from chronic kidney disease (CKD) (18-20). While quite capable in this regard with fewer androgenic side effects compared to testosterone (the previous standard of care), nandrolone's use in the treatment of anemia was largely supplanted in the late 1980s with the introduction of recombinant human erythropoietin (EPO) (21). Interestingly, nandrolone is still occasionally used as an alternative for select patients who cannot tolerate EPO and for patients in resource-limited countries (21-23). Outside of its historical indication for anemia, nandrolone has also shown promise in the treatment of osteoporosis and the sarcopenic states commonly observed in advanced chronic obstructive pulmonary disease (COPD), acquired immunodeficiency syndrome (AIDS), and end-stage renal disease (ESRD) (24-27). Unfortunately, nandrolone decanoate (ND) is no longer commercially available within the United States and, therefore, must be compounded.

\section{Side effects}

Nandrolone has been shown to possess a generally favorable side effect profile compared to most other AAS. Although any androgenic stimulation of the hair follicle and sebaceous sweat glands may result in alopecia, hirsutism, and acne, nandrolone's weak androgenic activity makes these side effects uncommon (28). As an injectable oil, nandrolone is not subject to first-pass hepatic metabolism 
and is not hepatotoxic. Interestingly, although not welldescribed in the literature, some users of nandrolone have complained of temporary ED that resolves with cessation of therapy (13). This anecdotal side effect appears to be highly dependent on nandrolone dosage and the use or absence of concomitant testosterone. Although further studies regarding this are needed, plausible mechanisms for this include the insufficient androgenic activity of nandrolone itself and negative-feedback induced suppression of the HPG axis resulting in both reduced testosterone and DHT, the latter of which crucial to nitric-oxide mediated erectile function $(13,29)$. Interference with the HPG axis also poses a significant risk to fertility and may risk the possibility for hypogonadism with long-term use in men who are not already testosterone deficient (30).

It is important to note that the majority of the literature, which describes the adverse effects of nandrolone, does so in the setting of illicit AAS abuse $(11,31,32)$. This patient population is notorious for utilizing very high doses of AAS and is fraught with polypharmacy. Thus, the usefulness of extrapolating these studies' findings to appropriate medical therapy with nandrolone is extremely limited (33). In human studies, illicit, long-term AAS abuse has been associated with cardiovascular complications, such as cardiomyopathy and coronary artery disease $(34,35)$. In rat models using approximately $20 \times$ the doses of nandrolone used clinically; cardiomyopathy has also been observed (36-38). It is unclear to what extent, if any, these risks would apply to nandrolone administration at a more reasonable dosage in a clinical setting. Thus far, the controlled clinical trials of nandrolone have been too small and too sparse to confidently assess the risks of physician-prescribed and monitored nandrolone treatment at appropriate dosing.

\section{Nandrolone and the musculoskeletal system}

Nandrolone's primarily anabolic effects have prompted an investigation into its effects on the musculoskeletal system, and, like other sex steroid hormones, it has also been examined for its effects on bone metabolism. The actions of androgens in bone metabolism are complex and not fully understood, but it is known that there is an AR-mediated role for non-aromatized androgens on bone, as evidenced by studies of AR knockout in mice which showed a marked increase in trabecular bone loss $(39,40)$. In osteoporosis, multiple studies have shown nandrolone to increase bone mineral density (BMD) (24,41-43). More importantly, this increase in BMD has been shown to translate into improved bone strength $(24,44)$. In 2005 , Frisoli et al. conducted a double-blind, randomized, placebo-controlled trial of nandrolone in osteoporotic elderly women, which supported these findings in addition to revealing a reduced vertebral fracture rate in the nandrolone group (24). Nandrolone also appears to be beneficial in the non-osteoporotic bone. In rodent studies, administration of nandrolone resulted in a reduction of the significant bone loss seen in denervation and spinal cord injuries in addition to improved fracture healing (45-47). Nandrolone's specific actions at the bone are also not entirely clear, but an AR-mediated effect is likely at least contributory.

The myotrophic effects of nandrolone have made its use in sarcopenic diseases, particularly appealing. Satellite cells, the skeletal muscle stem cells which play a key role in muscle regeneration, express ARs and appear to be essential to androgen-mediated muscle hypertrophy $(48,49)$. Nandrolone appears to stimulate myogenic progenitor cell differentiation via the upregulation of MyoD and Numb, a Notch inhibitor, in addition to activating calcineurin-NFAT signaling, which plays a role in the resulting muscle hypertrophy $(50,51)$. In addition, nandrolone increases local levels of IGF-1 with resulting skeletal muscle hypertrophy (52). Interestingly, blocking IGF-1 receptors attenuates the skeletal muscle response for androgens, but it does not fully prevent hypertrophy, confirming that IGF-1 signaling has an important, but not solitary, role in androgen-mediated skeletal muscle fiber hypertrophy (53). These mechanisms provide insight into the use of nandrolone in chronic muscle wasting diseases such as those seen in COPD, dialysis-dependent CKD, and AIDS $(26,27,54)$. Of note, Horstman et al. investigated the effect of a single dose of nandrolone at the time of full leg casting in young men and found no preservation of skeletal muscle mass or strength after 1 week (55). The lack of effect in this study may be due to the shorttime frame or the timing of administration. In fact, in rat models of denervation atrophy, nandrolone administration did not attenuate atrophy or alter gene expression over the following 14 days when dosing began at the time of denervation; however, nandrolone was effective when administered 28 days after denervation with significantly reduced atrophy at both 7 and 28 days later (56). These findings suggest that nandrolone's effects on muscle atrophy may be timing-dependent when measured in the very short-term.

With regards to nandrolone's influence on the 
musculoskeletal injury, there has been significant work evaluating nandrolone's effect on rotator cuff tendon tears using animal models. Chronic rotator cuff tears often result in irreversible muscle atrophy, fatty infiltration, and fibrosis, which makes successful repair difficult and outcomes poor $(57,58)$. In 2011, Gerber et al. published a very interesting study in which he released the supraspinatus tendon of twenty rabbits. Ten were administered intramuscular ND while the other ten were left as controls. The researchers then examined their supraspinatus retraction and evaluated the observed amount of fatty infiltration after 6 weeks. The group receiving intramuscular nandrolone had decreased supraspinatus retraction, decreased fatty infiltration, and increased muscle work under standardized contraction compared to controls (59). In a 2015 follow-up study, Gerber et al. performed a study with similar endpoints using a sheep model. In this study, eighteen alpine sheep underwent infraspinatus tendon released, followed by subsequent repair at 16 weeks and sacrificed at 22 weeks. Six sheep were administered $150 \mathrm{mg}$ of ND once weekly starting at the time of tendon release, while another six were administered the same dose starting at the time of tendon repair. The final 6 were left as controls. Researchers found that weekly administration of intramuscular nandrolone immediately following tendon release resulted in almost complete prevention of fatty infiltration over the following 22 weeks with the maintenance of lean muscle mass. Even when nandrolone administration was delayed until surgical repair at 16 weeks, further muscle atrophy was prevented over the following 6 weeks (58). Both these studies underscore nandrolone's considerable myogenic effects.

Of note, a later study in which local ND solution was injected directly into rabbits' repaired rotator cuff tendons resulted in poor healing with reduced tendon strength (60). However, the poor response in this study is postulated to have been related to the direct injection of nandrolone into the acutely damaged and repaired tendon while other studies opted for more traditional intramuscular administration. Still, concern exists that AAS weaken tendons despite being advantageous to the muscle itself (61). A recent systematic review examining the effects of AAS on tendon properties found the results to be highly heterogeneous and often contradictory (61). Further study is needed to characterize nandrolone's beneficial effects on rotator cuff repair better.

\section{Novel pilot study}

\section{Introduction}

Nandrolone's complex relationship with joint health extends beyond healing in the rotator cuff model. Interestingly, various members of online bodybuilding communities and discussion boards have frequently asserted that nandrolone alleviates joint pain (16). While there have been two doubleblind, placebo-controlled trials showing that nandrolone alleviates bone pain in post-menopausal osteoporosis, studies specifically evaluating joint pain are quite limited $(62,63)$. In 1987, Bird et al. conducted a controlled trial in postmenopausal women with rheumatoid arthritis in which the intervention arm received intramuscular ND $50 \mathrm{mg}$ every 3 weeks for 2 years finding no significant difference in joint or bone pain compared with the control arm as assessed by visual analog scales (64). Despite the equivocal findings in rheumatoid arthritis, there are two trials that, while limited, do support a role for nandrolone in the alleviation of non-inflammatory arthralgia. Darracott et al. found that, compared to placebo, weekly intramuscular ND resulted in clinically improved symptoms and patellar bone density measurements after 6 weeks in patients with patellofemoral pain syndrome, a condition in which patients experience peripatellar pain at the patellofemoral joint $(65,66)$. More recently, Hohmann et al. conducted a double-blind, placebo-controlled randomized trial of ND in 10 patients who underwent total knee arthroplasty and were followed for 1 year. They found a significant improvement in quadriceps strength throughout the post-operative period in addition to improved Knee Society Score (KSS) at 6 weeks, 6 months, and 12 months in the group receiving nandrolone (67). The KSS includes an assessment of knee pain in its composite score but, unfortunately, the authors did not report the pain subscore specifically (68). Therefore, while promising, it is unclear if this study provides any evidence about nandrolone's prospective use for joint pain.

As evidenced above, there is very little concrete data referencing any effect nandrolone may have regarding the alleviation of joint pain. However, nandrolone does have well-documented advantageous effects on bone and muscle along with quality trials showing its benefit in osteoporotic bone pain and historical documentation of its efficacy for patellofemoral pain syndrome. Therefore, it is reasonable to postulate that the anecdotal evidence ascribing non-inflammatory joint pain relief to nandrolone 
may be accurate. Additionally, male hypogonadism is linked with comorbidities such as diabetes and obesity, which are often associated with significant and debilitating joint pain $(69,70)$. In such patients, the addition of nandrolone to their testosterone replacement regimen would avoid the potential side effect of ED, as discussed earlier, resulting in a highlytolerable option for pain management, if efficacious.

\section{The objective of the pilot study}

Due to the paucity of research surrounding nandrolone and objective measurement of non-inflammatory joint painwe designed a novel prospective pilot study to evaluate, quantify, and characterize the effects of ND on joint pain in hypogonadal men.

\section{Methods}

\section{Study participants}

All adult men with the diagnosis of hypogonadism (confirmed by sequential morning serum testosterone value of less than $300 \mathrm{ng} / \mathrm{dL}$ ) who were currently using injectable intramuscular TTh were screened for the presence of joint pain at a single high-volume andrology clinic in Houston, Texas from August 2018 to January 2019. Inclusion criteria were men, aged 2170 years old, confirmed diagnosis of hypogonadism currently treated with injectable intramuscular TTh, and report of significant joint pain at the screening. Exclusion criteria included prior nandrolone usage, inability to give informed consent, inability to perform intramuscular self-injection, an earlier diagnosis of solid organ cancer, and significant cardiovascular disease. All participants gave informed consent before inclusion in the study. The proposed study was reviewed and approved by our institutional review board.

\section{Intervention}

Eligible participants initiated intramuscular ND dosed at one-half of their current testosterone cypionate regimen (e.g., a participant using $200 \mathrm{mg}$ testosterone cypionate weekly would continue that dose in addition to beginning $100 \mathrm{mg}$ ND weekly). All other medications, including testosterone dosage, were kept constant throughout the trial period. The dose of ND was also kept constant until all data was collected.

\section{Assessments}

There are few objective pain scales to quantify joint pain. The most commonly used is the visual analog scale, but this is overly simplistic as pain is multifaceted with a variety of descriptors and qualifiers in addition to a profound psychologic component (71). The Rheumatoid Arthritis Pain Scale (RAPS) is a validated questionnaire initially developed to assess and characterize pain levels in adults with rheumatoid arthritis. It consists of 24 statements about joint pain to which patients assign a value ranging from 0 (never) to 6 (always). The administrator totals these pain scores with higher scores signifying worse pain. The scores can then be divided into physiologic, affective, sensory-discriminative, and cognitive components (71). This scale was chosen as it offers a more comprehensive assessment into a patient's personal experience of joint pain.

Each participant completed the RAPS before starting ND and 8 weeks after initiating ND. At initial RAPS administration, patient-specific characteristics were also recorded. This included the location of pain along with current pain medication usage and dosages.

\section{Statistical analysis}

As the data were normally distributed, the difference between pre-ND and post-ND RAPS scores was analyzed via paired $t$-tests. Data were considered statistically significant when $\mathrm{P}<0.05$.

\section{Results}

Forty-eight eligible patients completed the initial survey, and 18 men $(37.5 \%)$ responded to follow-up requests. The median duration of therapy was 62 [interquartile range (IQR), 48-73] days, and the median dose of ND was 110 (IQR, 100-150) mg. Participants' mean age was 46 [standard deviation (SD), 11] years old with a racial makeup consisting of 15 Caucasian, 2 Hispanic, and 1 African American.

Of the 18 men who responded to their follow-up request, $13(72.2 \%)$ reported marked improvements in joint pain, with $5(27.8 \%)$ reporting a decreased need for longstanding pain medication. Amongst responding patients, pain scores were reduced on average by $52 \%$. Even when accounting for treatment non-responders, the collective improvement in pain scores observed across each of the 4 sub-categories of the RAPS was both statistically significant and profound (Figure 2). No adverse events were noted.

\section{Discussion}

Although limited by small follow-up sample size, 


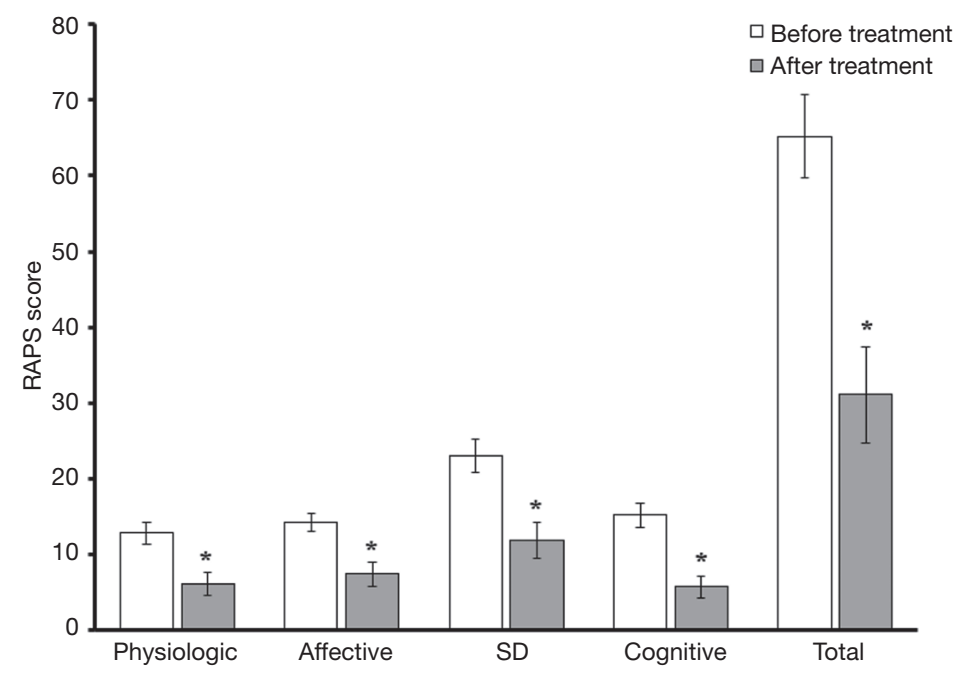

Figure 2 Mean RAPS scores before and after ND treatment. *, $\mathrm{P}<0.05$. RAPS, Rheumatoid Arthritis Pain Scale; ND, nandrolone decanoate; $\mathrm{SD}$, standard deviation.

nandrolone appears to exert a marked effect on joint pain as measured by the RAPS. Responding patients reported that their discomfort was reduced on average by more than half. Notably, many patients also reported a decreased reliance on chronic pain medication, which included longstanding narcotic prescriptions from other providers. Reducing narcotic utilization is paramount in today's opioid crisis climate. Further studies are required to characterize ND's effects across a larger study population better and understand its efficacy.

\section{Conclusions}

For decades, testosterone has been the sole instrument in the andrologist's arsenal for the ongoing treatment and management of male hypogonadism. However, with increased interest and emerging research, there now exist more options than ever to help combat the sequelae of this devastating clinical condition. Nandrolone is a particularly compelling medication that has significant beneficial effects on joint pain in hypogonadal men, reducing their reliance on chronic pain medication and reducing pain scores in responding men by more than half. Although further studies are required to replicate and characterize these findings on a larger scale, they suggest a novel indication for a fascinating drug that appears to hold great promise for future clinical use. It is increasingly apparent that the field of modern andrology is evolving rapidly with ever-expanding options to assist our patients in novel and exciting ways.

\section{Acknowledgments}

The authors would like to thank Empower Pharmacy, based in Houston, TX, USA, for provision of the nandrolone decanoate used in this study.

Funding: None.

\section{Footnote}

Provenance and Peer Review: This article was commissioned by the Guest Editors (Larry I. Lipshultz, Alexander W. Pastuszak) for the focused issue "Contemporary Issues and Controversies in Men's Health" published in Translational Andrology and Urology. The article was sent for external peer review organized by the Guest Editors and the editorial office.

Conflicts of Interest: The focused issue "Contemporary Issues and Controversies in Men's Health" was commissioned by the editorial office without any funding or sponsorship. LIL serves as an unpaid editorial board member of Translational Andrology and Urology from Nov 2019 to Oct 2021 and served as the unpaid Guest Editor of the focused issue. Dr. Kovac: Abbvie (Consultant). Dr. Lipshultz: American Medical Systems (Speaker); AbbVie (Consultant); Lipocine (Consultant); Aytu Bioscience (Consultant); Endo Pharmaceuticals (Speaker/ Consultant). The other authors have no conflicts of interest to declare. 
Ethical Statement: The authors are accountable for all aspects of the work in ensuring that questions related to the accuracy or integrity of any part of the work are appropriately investigated and resolved.

Open Access Statement: This is an Open Access article distributed in accordance with the Creative Commons Attribution-NonCommercial-NoDerivs 4.0 International License (CC BY-NC-ND 4.0), which permits the noncommercial replication and distribution of the article with the strict proviso that no changes or edits are made and the original work is properly cited (including links to both the formal publication through the relevant DOI and the license). See: https://creativecommons.org/licenses/by-nc$\mathrm{nd} / 4.0 \%$.

\section{References}

1. Dohle GR, Arver S, Bettocchi C, et al. EAU guidelines on male hypogonadism. 2016. Available online: https:// uroweb.org/wp-content/uploads/EAU-Guidelines-MaleHypogonadism-2016-1.pdf

2. Corona G, Maggi M. The role of testosterone in erectile dysfunction. Nat Rev Urol 2010;7:46-56.

3. Finkelstein JS, Lee H, Burnett-Bowie SA, et al. Gonadal steroids and body composition, strength, and sexual function in men. N Engl J Med 2013;369:1011-22.

4. Srinivas-Shankar U, Roberts SA, Connolly MJ, et al. Effects of testosterone on muscle strength, physical function, body composition, and quality of life in intermediate-frail and frail elderly men: a randomized, double-blind, placebocontrolled study. J Clin Endocrinol Metab 2010;95:639-50.

5. Isidori AM, Giannetta E, Greco EA, et al. Effects of testosterone on body composition, bone metabolism and serum lipid profile in middle-aged men: a meta-analysis. Clin Endocrinol (Oxf) 2005;63:280-93.

6. Kloner RA, Carson C, Dobs A, et al. Testosterone and cardiovascular disease. J Am Coll Cardiol 2016;67:545-57.

7. Corona G, Rastrelli G, Monami M, et al. Hypogonadism as a risk factor for cardiovascular mortality in men: a metaanalytic study. Eur J Endocrinol 2011;165:687-701.

8. Hackett G, Cole N, Mulay A, et al. Long-term testosterone therapy in type 2 diabetes is associated with reduced mortality without improvement in conventional cardiovascular risk factors. BJU Int 2019;123:519-29.

9. Hackett G, Cole N, Bhartia M, et al. Testosterone replacement therapy improves metabolic parameters in hypogonadal men with type 2 diabetes but not in men with coexisting depression: the BLAST study. J Sex Med 2014;11:840-56.

10. Jones TH, Arver S, Behre HM, et al. Testosterone replacement in hypogonadal men with type 2 diabetes and/or metabolic syndrome (the TIMES2 study). Diabetes Care 2011;34:828-37.

11. Kicman AT. Pharmacology of anabolic steroids. Br J Pharmacol 2008;154:502-21.

12. Birch AJ. 80. Hydroaromatic steroid hormones. Part I. 10-nortestosterone. J Chem Soc Resumed 1950:367-8.

13. Pan MM, Kovac JR. Beyond testosterone cypionate: evidence behind the use of nandrolone in male health and wellness. Transl Androl Urol 2016;5:213-19.

14. Eisenberg E, Gordan GS. The levator ani muscle of the rat as an index of myotrophic activity of steroidal hormones. J Pharmacol Exp Ther 1950;99:38-44.

15. Hershberger LG, Shipley EG, Meyer RK. Myotrophic activity of 19-nortestosterone and other steroids determined by modified levator ani muscle method. Proc Soc Exp Biol Med 1953;83:175-80.

16. Potts GO, Arnold A, Beyler AL. Dissociation of the androgenic and other hormonal activities from the protein anabolic effects of steroids. In: Kochakian CD. editor. Anabolic-androgenic steroids. Heidelberg: Springer, 1976:361-406.

17. Tóth $M$, Zakár T. Relative binding affinities of testosterone, 19-nortestosterone and their $5 \alpha$-reduced derivatives to the androgen receptor and to other androgen-binding proteins: a suggested role of $5 \alpha$-reductive steroid metabolism in the dissociation of "myotropic" and "androgenic" activities of 19-nortestosterone. J Steroid Biochem 1982;17:653-60.

18. Hervé L, Daiber A, Con I, et al. Treatment of aplastic anemia with nandrolone decanoate. Blood 1970;36:748-53.

19. Williams JS, Stein JH, Ferris TF. Nandrolone decanoate therapy for patients receiving hemodialysis. A controlled study. Arch Intern Med 1974;134:289-92.

20. Cattran DC, Fenton SS, Wilson DR, et al. A controlled trial of nondrolone decanoate in the treatment of uremic anemia. Kidney Int 1977;12:430-37.

21. Gascón A, Belvis JJ, Berisa F, et al. Nandrolone decanoate is a good alternative for the treatment of anemia in elderly male patients on hemodialysis. Geriatr Nephrol Urol 1999;9:67-72.

22. Kliger AS, Foley RN, Goldfarb DS, et al. KDOQI US commentary on the 2012 KDIGO clinical practice guideline for anemia in CKD. Am J Kidney Dis 2013;62:849-59. 
23. Adamu B, Ma'aji SM, Erwin PJ, et al. Meta-analysis of randomized controlled trials on androgens versus erythropoietin for anaemia of chronic kidney disease: implications for developing countries. Int J Nephrol 2012;2012:580437.

24. Frisoli A Jr, Chaves PH, Pinheiro MM, et al. The effect of nandrolone decanoate on bone mineral density, muscle mass, and hemoglobin levels in elderly women with osteoporosis: a double-blind, randomized, placebo-controlled clinical trial. J Gerontol A Biol Sci Med Sci 2005;60:648-53.

25. Mulligan K, Zackin R, Clark RA, et al. Effect of nandrolone decanoate therapy on weight and lean body mass in HIV-infected women with weight loss: a randomized, double-blind, placebo-controlled, multicenter trial. Arch Intern Med 2005;165:578-85.

26. Johansen KL, Painter PL, Sakkas GK, et al. Effects of resistance exercise training and nandrolone decanoate on body composition and muscle function among patients who receive hemodialysis: a randomized, controlled trial. J Am Soc Nephrol JASN 2006;17:2307-14.

27. Creutzberg EC, Wouters EF, Mostert R, et al. A role for anabolic steroids in the rehabilitation of patients with COPD? A double-blind, placebo-controlled, randomized trial. Chest 2003;124:1733-42.

28. Walker J, Adams B. Cutaneous manifestations of anabolicandrogenic steroid use in athletes. Int J Dermatol 2009;48:1044-8; quiz 1048.

29. Lugg JA, Rajfer J, González-Cadavid NF. Dihydrotestosterone is the active androgen in the maintenance of nitric oxide-mediated penile erection in the rat. Endocrinology 1995;136:1495-501.

30. Coward RM, Rajanahally S, Kovac JR, et al. Anabolic steroid induced hypogonadism in young men. J Urol 2013;190:2200-05.

31. Graham S, Kennedy M. Recent developments in the toxicology of anabolic steroids. Drug Saf 1990;5:458-76.

32. Alsiö J, Birgner C, Björkblom L, et al. Impact of nandrolone decanoate on gene expression in endocrine systems related to the adverse effects of anabolic androgenic steroids. Basic Clin Pharmacol Toxicol 2009; 105:307-14.

33. Sagoe D, McVeigh J, Bjørnebekk A, et al. Polypharmacy among anabolic-androgenic steroid users: a descriptive metasynthesis. Subst Abuse Treat Prev Policy 2015;10:12.

34. Baggish Aaron L, Weiner Rory B, Kanayama Gen, et al. Cardiovascular toxicity of illicit anabolic-androgenic steroid use. Circulation 2017;135:1991-2002.

35. Baggish Aaron L, Weiner Rory B, Kanayama Gen, et al.
Long-term anabolic-androgenic steroid use is associated with left ventricular dysfunction. Circ Heart Fail 2010;3:472-76.

36. Franquni JVM, do Nascimento AM, de Lima EM, et al. Nandrolone decanoate determines cardiac remodelling and injury by an imbalance in cardiac inflammatory cytokines and ACE activity, blunting of the Bezold-Jarisch reflex, resulting in the development of hypertension. Steroids 2013;78:379-85.

37. Tofighi A, Shirpoor M, Ansari MHK, et al. The effect of nandrolone treatment with and without enforced swimming on histological and biochemical changes in the heart and coronary artery of male rats. Anatol J Cardiol 2017;17:176-83.

38. Frankenfeld SP, Oliveira LP, Ortenzi VH, et al. The anabolic androgenic steroid nandrolone decanoate disrupts redox homeostasis in liver, heart and kidney of male Wistar rats. PloS One 2014;9:e102699.

39. Vanderschueren D, Laurent MR, Claessens F, et al. Sex steroid actions in male bone. Endocr Rev 2014;35:906-60.

40. Venken K, De Gendt K, Boonen S, et al. Relative impact of androgen and estrogen receptor activation in the effects of androgens on trabecular and cortical bone in growing male mice: a study in the androgen receptor knockout mouse model. J Bone Miner Res 2006;21:576-85.

41. Need AG, Chatterton BE, Walker CJ, et al. Comparison of calcium, calcitriol, ovarian hormones and nandrolone in the treatment of osteoporosis. Maturitas 1986;8:275-80.

42. Geusens P, Dequeker J. Long-term effect of nandrolone decanoate, 1 alpha-hydroxyvitamin D3 or intermittent calcium infusion therapy on bone mineral content, bone remodeling and fracture rate in symptomatic osteoporosis: a double-blind controlled study. Bone Miner 1986;1:347-57.

43. Need AG, Morris HA, Hartley TF, et al. Effects of nandrolone decanoate on forearm mineral density and calcium metabolism in osteoporotic postmenopausal women. Calcif Tissue Int 1987;41:7-10.

44. Gadeleta SJ, Boskey AL, Paschalis E, et al. A physical, chemical, and mechanical study of lumbar vertebrae from normal, ovariectomized, and nandrolone decanoatetreated cynomolgus monkeys (Macaca fascicularis). Bone 2000;27:541-50.

45. Cardozo CP, Qin W, Peng Y, et al. Nandrolone slows hindlimb bone loss in a rat model of bone loss due to denervation. Ann N Y Acad Sci 2010;1192:303-06.

46. Sun L, Pan J, Peng Y, et al. Anabolic steroids reduce spinal 
cord injury-related bone loss in rats associated with increased Wnt signaling. J Spinal Cord Med 2013;36:616-22.

47. Ahmad F, Yunus SM, Asghar A, et al. Influence of anabolic steroid on tibial fracture healing in rabbits - a study on experimental model. J Clin Diagn Res 2013;7:93-6.

48. Solomon AM, Bouloux PMG. Modifying muscle mass the endocrine perspective. J Endocrinol 2006;191:349-60.

49. Yin H, Price F, Rudnicki MA. Satellite Cells and the Muscle Stem Cell Niche. Physiol Rev 2013;93:23-67.

50. Qin W, Pan J, Wu Y, et al. Anabolic steroids activate calcineurin-NFAT signaling and thereby increase myotube size and reduce denervation atrophy. Mol Cell Endocrinol 2015;399:336-45.

51. Liu XH, De Gasperi R, Bauman WA, et al. Nandroloneinduced nuclear accumulation of MyoD protein is mediated by Numb, a Notch inhibitor, in C2C12 myoblasts. Physiol Rep 2018. doi: 10.14814/phy2.13520.

52. Lewis MI, Horvitz GD, Clemmons DR, et al. Role of IGF-I and IGF-binding proteins within diaphragm muscle in modulating the effects of nandrolone. Am J Physiol Endocrinol Metab 2002;282:E483-90.

53. Serra C, Bhasin S, Tangherlini F, et al. The role of GH and IGF-I in mediating anabolic effects of testosterone on androgen-responsive muscle. Endocrinology 2011;152:193-206.

54. Gold J, Batterham MJ, Rekers H, et al. Effects of nandrolone decanoate compared with placebo or testosterone on HIVassociated wasting. HIV Med 2006;7:146-55.

55. Horstman AMH, Backx EMP, Smeets JSJ, et al. Nandrolone decanoate administration does not attenuate muscle atrophy during a short period of disuse. PLoS One 2019;14:e0210823.

56. Zhao J, Zhang Y, Zhao W, et al. Effects of nandrolone on denervation atrophy depend upon time after nerve transection. Muscle Nerve 2008;37:42-9.

57. Gerber C, Fuchs B, Hodler J. The results of repair of massive tears of the rotator cuff. J Bone Joint Surg Am 2000;82:505-15.

58. Gerber C, Meyer DC, Flück M, et al. Anabolic steroids reduce muscle degeneration associated with rotator cuff tendon release in sheep. Am J Sports Med 2015;43:2393-400.

59. Gerber C, Meyer DC, Nuss KM, et al. Anabolic steroids reduce muscle damage caused by rotator cuff tendon release in an experimental study in rabbits. J Bone Joint Surg Am 2011;93:2189-95.

60. Papaspiliopoulos A, Papaparaskeva K, Papadopoulou E, et al. The effect of local use of nandrolone decanoate on rotator cuff repair in rabbits. J Invest Surg 2010;23:204-7.

61. Jones IA, Togashi R, Hatch GFR 3rd, et al. Anabolic steroids and tendons: a review of their mechanical, structural, and biologic effects. J Orthop Res 2018;36:2830-41.

62. Passeri M, Pedrazzoni M, Pioli G, et al. Effects of nandrolone decanoate on bone mass in established osteoporosis. Maturitas 1993;17:211-19.

63. Lyritis GP, Androulakis C, Magiasis B, et al. Effect of nandrolone decanoate and 1- $\alpha$-hydroxy-calciferol on patients with vertebral osteoporotic collapse. A doubleblind clinical trial. Bone Miner 1994;27:209-17.

64. Bird HA, Burkinshaw L, Pearson D, et al. A controlled trial of nandrolone decanoate in the treatment of rheumatoid arthritis in postmenopausal women. Ann Rheum Dis 1987;46:237-43.

65. Heintjes EM, Berger M, Bierma-Zeinstra SMA, et al. Pharmacotherapy for patellofemoral pain syndrome. Cochrane Database Syst Rev 2004. doi: 10.1002/14651858. CD003470.pub2.

66. Darracott J. Treatment of the painful knee fulfilling diagnostic criteria for 'chondromalacia patellae'. Curr Med Res Opin 1973;1:412-22.

67. Hohmann E, Tetsworth K, Hohmann S, et al. Anabolic steroids after total knee arthroplasty. A double blinded prospective pilot study. J Orthop Surg Res 2010;5:93.

68. Insall JN, Dorr LD, Scott RD, et al. Rationale of the Knee Society clinical rating system. Clin Orthop 1989:13-4.

69. Bhasin S, Cunningham GR, Hayes FJ, et al. Testosterone therapy in men with androgen deficiency syndromes: an endocrine society clinical practice guideline. J Clin Endocrinol Metab 2010;95:2536-59.

70. Barbour KE, Boring M, Helmick CG, et al. Prevalence of severe joint pain among adults with doctor-diagnosed arthritis - United States, 2002-2014. MMWR Morb Mortal Wkly Rep 2016;65:1052-6.

71. Anderson DL. Development of an instrument to measure pain in rheumatoid arthritis: Rheumatoid Arthritis Pain Scale (RAPS). Arthritis Rheum 2001;45:317-23.

Cite this article as: Tatem AJ, Holland LC, Kovac J, Beilan JA, Lipshultz LI. Nandrolone decanoate relieves joint pain in hypogonadal men: a novel prospective pilot study and review of the literature. Transl Androl Urol 2020;9(Suppl 2):S186-S194. doi: 10.21037/tau.2019.11.03 